\title{
What Does the Pipeline Promise about Upcoming Biosimilar Antibodies in Oncology?
}

\author{
Antonia Busse Diana Lüftner \\ Medical Department of Hematology, Oncology and Tumor Immunology, Charité - Universitätsmedizin Berlin, \\ corporate member of Freie Universität Berlin, Humboldt-Universität zu Berlin, and Berlin Institute of Health, Campus \\ Benjamin Franklin, Berlin, Germany
}

Keywords

Biosimilar · Trastuzumab · Rituximab · Bevacizumab · Cetuximab

\begin{abstract}
The introduction of biosimilars of biological agents for which the patents and exclusivity periods have expired is an attractive way of reducing healthcare spending through price competition with the reference product. In oncology, biosimilars of growth factors for supportive therapy were the pioneers; now, monoclonal antibody biosimilars are conquering the market. In Europe, this is currently limited to biosimilars of the monoclonal antibodies trastuzumab and rituximab. However, the pipeline is full and several monoclonal antibody biosimilars in oncology are now in late-stage development. We are expecting not only more biosimilar versions of the top 3 blockbuster monoclonal antibodies, trastuzumab, rituximab and bevacizumab, to enter the market; as patent expiration of multiple other cancer biologicals will occur in the next few years, the biosimilar landscape will become much more diversified. Several biosimilars of monoclonal antibodies used in targeted therapy such as cetuximab, pertuzumab, or denosumab are in early development.

๑ 2019 S. Karger AG, Basel

\section{Introduction: Rationale for Biosimilar Development}

Over the last 20 years, significant progress has been made in cancer therapy through the continuous development of new biologicals, notably monoclonal antibodies [1]. However, these new treatment options come with a significant escalation of healthcare costs. Monoclonal antibodies are usually large proteins with a complex structure. They are produced in a complex biotechnological process in living genetically modified microorganisms or cells; this is why they are much more expensive than other medicines. Biologicals now dominate the top 10 list of best-selling drugs in Europe: in 2017, 7 of the top 10 bestselling drugs were biologicals [2]. Moreover, several of the recently approved monoclonal antibodies in oncology including checkpoint inhibitors like nivolumab or pembrolizumab were predicted to become blockbusters in 2019 and 2020 [3, 4]. Consequently, patient access to biologicals is often limited by high costs. The introduction of biosimilars for biologicals where the patents and exclusivity periods have expired to the market is an attractive way of reducing healthcare spending through price competition with the reference product [2].

A biosimilar is a biological medicinal product that contains a version of the active substance of an already 
Table 1. Blockbuster monoclonal antibodies and their patent and exclusivity expiry dates in Europe and the US (adapted from [15])

\begin{tabular}{|c|c|c|}
\hline & Europe & US \\
\hline Adcetris ${ }^{\circledR} /$ brentuximab - vedotin & August 2023 & $2015-2031$ \\
\hline Avastin ${ }^{\circledR} /$ bevacizumab & January 2022 & July 2019 \\
\hline Arzerra ${ }^{\circledR} /$ ofatumumab & data not available & December 2018 \\
\hline Campath $^{\circledR} /$ alemtuzumab & May 2021 & July 2021 \\
\hline Cyramza $^{\circledR} /$ ramucirumab & May 2023 & November 2025 \\
\hline Darzalex ${ }^{\circledR} /$ daratumumab & May 2026 & February 2025 \\
\hline Erbitux $^{\circledR} /$ cetuximab & June 2014 & February 2016 \\
\hline Gazyvaro ${ }^{\circledR}$, Gazyva ${ }^{\circledR} /$ obinutuzumab & November 2024 & January 2035 \\
\hline Herceptin ${ }^{\circledR} /$ trastuzumab & August 2015 & June 2019 \\
\hline Kadcyla $^{\circledR} /$ trastuzumab emtansine & June 2020 & September 2026 \\
\hline Keytruda ${ }^{\circledR} /$ pembrolizumab & June 2028 & November 2036 \\
\hline Mabthera ${ }^{\circledR}$, Rituxan ${ }^{\circledR} /$ rituximab & November 2013 & September 2016 \\
\hline Opdivo ${ }^{\circledR} /$ nivolumab & May 2026 & June 2027 \\
\hline Perjeta ${ }^{\circledR} /$ pertuzumab & May 2023 & June 2024 \\
\hline Prolia $^{\circledR}$, Xgeva ${ }^{\circledR} /$ denosumab & June 2022 & February 2025 \\
\hline Tecentriq ${ }^{\circledR} /$ atezolizumab & September 2027 & May 2028 \\
\hline Vectibix ${ }^{\circledR} /$ panitumumab & 2018 & April 2020 \\
\hline Yervoy ${ }^{\circledR} /$ ipilimumab & 2021 & 2023 \\
\hline
\end{tabular}

authorized original biological medicinal product (reference medicinal product) [5]. Similarity to the reference medicinal product in quality, biological activity, safety, immunogenicity, and efficacy has to be established on the basis of an extensive comparability exercise. Biosimilars are thus designed to be used interchangeably with biologicals and are at least equipotent. Sometimes they show a trend for superior efficacy, albeit within the strict equivalence limits. 'Similar' refers to the same corridor of microheterogeneity as applies to the reference medicinal product at each new batch or change in the manufacturing process [6]. An important factor responsible for microheterogeneity is the variability of the glycosylation pattern. This pattern can be affected by the expression system, cell culture conditions, and method of antibody purification. Therefore, glycosylation patterns differ whenever the manufacturing process for an antibody is modified [7]. Since the glycosylation pattern affects protein function including antibody-dependent cell-mediated cytotoxicity, clinical efficacy might not only differ between a reference product and its biosimilar, but also between different lots of a reference product. This has been shown for several antibodies, among them rituximab (Mabthera ${ }^{\circledR}$; Roche, Basel, Switzerland) and trastuzumab (Herceptin ${ }^{\circledR}$; Roche) $[8,9]$.

The manufacturing process, as with the reference product, is still very expensive. However, a biosimilar is less clinically tested than its reference biological. This ultimately reduces its costs. In Europe, price reductions for biosimilars are expected to range from 20 to $40 \%$, with a few cases being higher [10]. According to estimates, cost savings will amount to more than EUR 10 billion between 2016 and 2020 in the EU5 countries [11]. However, the financial impact might never reach that of generic drugs competition. This is due to significant differences in development and regulatory processes between generics and biosimilars.

\section{Current and Candidate Monoclonal Antibody Biosimilars in Oncology}

Currently, most biosimilar products available for oncology are in supportive care therapy. Filgrastim and epoetin are 2 biological medicines that offer significant benefits in cancer care and that are now patent-expired. Biosimilar versions of both have been approved in Europe by the European Medicines Agency (EMA) since 2007 and have proven to increase access to supportive cancer care [12-14]. Their use is increasing rapidly.

However, it is expected that the focus will shift to biologicals with life-prolonging effects such as monoclonal antibodies. The suppliers of most biologicals have not yet had to face competition from 'generic' products. However, this is going to change gradually as a number of high-volume monoclonal antibodies lose their patent protection and defined periods of market exclusivity expire [15] (table 1). Therefore, many companies have launched biosimilar development programs. So far, the focus has been mainly on the blockbuster monoclonal antibodies, rituximab, bevacizumab and trastuzumab.

The first so-called biocopies (including biogenerics, similar biologicals) for rituximab (e.g., $\operatorname{Redigit}^{\circledR} ;$ Dr. Reddy's Laboratories, Hyderabad, India) have been distributed for years in countries such as India, South America, and Russia. However, they have not been approved under the stringent scientific standards that apply to biosimilars in the EU [16]. 
Table 2. Approved biosimilars for monoclonal antibodies in oncology

\begin{tabular}{|c|c|c|c|c|}
\hline $\begin{array}{l}\text { Reference product/trade } \\
\text { name }\end{array}$ & $\begin{array}{l}\text { Biosimilar product } \\
\text { name/trade name }\end{array}$ & $\begin{array}{l}\text { Second } \\
\text { brand }\end{array}$ & Manufacturer & Phase III trial in oncology/indication \\
\hline \multirow[t]{2}{*}{$\begin{array}{l}\text { Rituximab/Mabthera }{ }^{\circledR}, \\
\text { Rituxan }^{\circledR}\end{array}$} & GP2013/Rixathon ${ }^{\circledR}$ & Riximyo $^{\circledR}$ & Sandoz & $\begin{array}{l}\text { ASSIST_FL, NCT01419665/previously untreated } \\
\text { advanced-stage follicular lymphoma [21] }\end{array}$ \\
\hline & CT-P10/Truxima ${ }^{\circledR}$ & $\begin{array}{l}\text { Blitzima }{ }^{\circledR}, \\
\text { Ritemvia }^{\circledR} \\
\text { Rituzena }^{\circledR}\end{array}$ & Celltrion & $\begin{array}{l}\text { NCT02162771/previously untreated advanced- } \\
\text { stage follicular lymphoma [19] }\end{array}$ \\
\hline \multirow[t]{5}{*}{ Trastuzumab/Herceptin $^{\circledR}$} & ${ }^{8 T-P 6 / H e r z u m a ~}{ }^{\circledR}$ & & Celltrion & NCT02162667/neoadjuvant HER2+ BC [45] \\
\hline & ABP 980/Kanjinti ${ }^{\circledR}$ & & Amgen & $\begin{array}{l}\text { LILAC, NCT01901146/neoadjuvant HER2+ BC } \\
\text { [46] }\end{array}$ \\
\hline & SB3/Ontruzant ${ }^{\circledR}$ & & Samsung Bioepis & NCT02149524/neoadjuvant HER2+ BC [47] \\
\hline & $\begin{array}{l}\text { PF-05280014/ } \\
\text { Trazimera }^{\circledR}\end{array}$ & & Pfizer & $\begin{array}{l}\text { REFLECTIONS B327-02, NCT01989676/ } \\
\text { 1st-line HER2+ metastatic BC } \\
\text { REFLECTIONS B327-04, NCT02187744/ } \\
\text { neoadjuvant HER2+ BC }[48,49]\end{array}$ \\
\hline & Ogivri $^{\circledR}$ & & Mylan/Biocon & $\begin{array}{l}\text { HERITAGE, NCT02472964/1st-line HER2+ met- } \\
\text { astatic BC [50] }\end{array}$ \\
\hline Bevacizumab/Avastin $^{\circledR}$ & ABP $215 /$ Mvasi $^{\circledR}$ & & Amgen & $\begin{array}{l}\text { NCT01966003/advanced or recurrent NSCLC } \\
{[51]}\end{array}$ \\
\hline
\end{tabular}

BC, breast cancer; NSCLC, non-small cell lung cancer.

To date (October 2018), 6 rituximab, 1 bevacizumab, and 5 trastuzumab biosimilars have been approved (table 2). Moreover, 2 rituximab biosimilars, 1 bevacizumab biosimilar, and 1 trastuzumab biosimilar are currently under evaluation by the Committee for Medicinal Products for Human Use (October 18, 2018) [17], and several other oncology biosimilars are currently in late-stage clinical development after successful completion of phase I trials.

\section{Rituximab}

As the first therapeutic monoclonal antibody in oncology, rituximab is also one of the first to encounter competition from biosimilar products as its patent expired in 2013 and 2016 in Europe and the US, respectively. Rituximab has been approved in Europe under the trade name Mabthera since 1998 for the treatment of non-Hodgkin's lymphoma (NHL) of the B-cell series. In 2006, the approval was extended for the treatment of severe active rheumatoid arthritis, granulomatosis with polyangiitis (Wegener's granulomatosis), and microscopic polyangiitis [18].

In February 2017, the first rituximab biosimilar, CTP10 (Celltrion, Incheon, ROK), was approved in the EU under the trade name Truxima ${ }^{\circledR}$ based on a phase III study in patients with advanced-stage follicular lymphoma showing comparable efficacy, safety, and immunogenicity [19]. Authorization was granted for all indications of the reference medicinal product [20].
Interestingly, CT-P10 is marketed under 3 more names, Rituzena ${ }^{\circledR}$, Ritemvia ${ }^{\circledR}$, and Blitzima ${ }^{\circledR}$, although with different marketing authorization: unlike Ritemvia, Blitzima and Rituzena have no indication for chronic lymphocytic leukemia (CLL). Celltrion believes that this somewhat unusual tactic could ultimately generate a larger market share. It offers the possibility to hand out distribution rights to different companies that could compete against each other and thereby maximize the market share of CT-P10 compared to the biosimilars of the competitors. The company already used the same strategy with its infliximab biosimilar, which is marketed under 2 names - Inflectra ${ }^{\circledR}$ (Pfizer, New York, NY, USA) and Remsima ${ }^{\circledR}$ (Celltrion).

In June 2017, GP2013 (Sandoz, Holzkirchen, Germany) was approved [21]. It is marketed under the trade names Riximyo ${ }^{\circledR}$, indicated for the treatment of NHL, and Rixathon ${ }^{\circledR}$, indicated for the treatment of NHL and CLL (table 2). Several other rituximab biosimilars are currently under clinical investigation in ongoing trials (fig. 1).

\section{Bevacizumab}

Bevacizumab (Avastin ${ }^{\circledR}$, Roche) is a monoclonal antibody directed against vascular endothelial growth factor A (VEGF-A), a central player in tumor angiogenesis and metastasis. Bevacizumab is approved in Europe for the treatment of a range of cancers, including metastatic or 


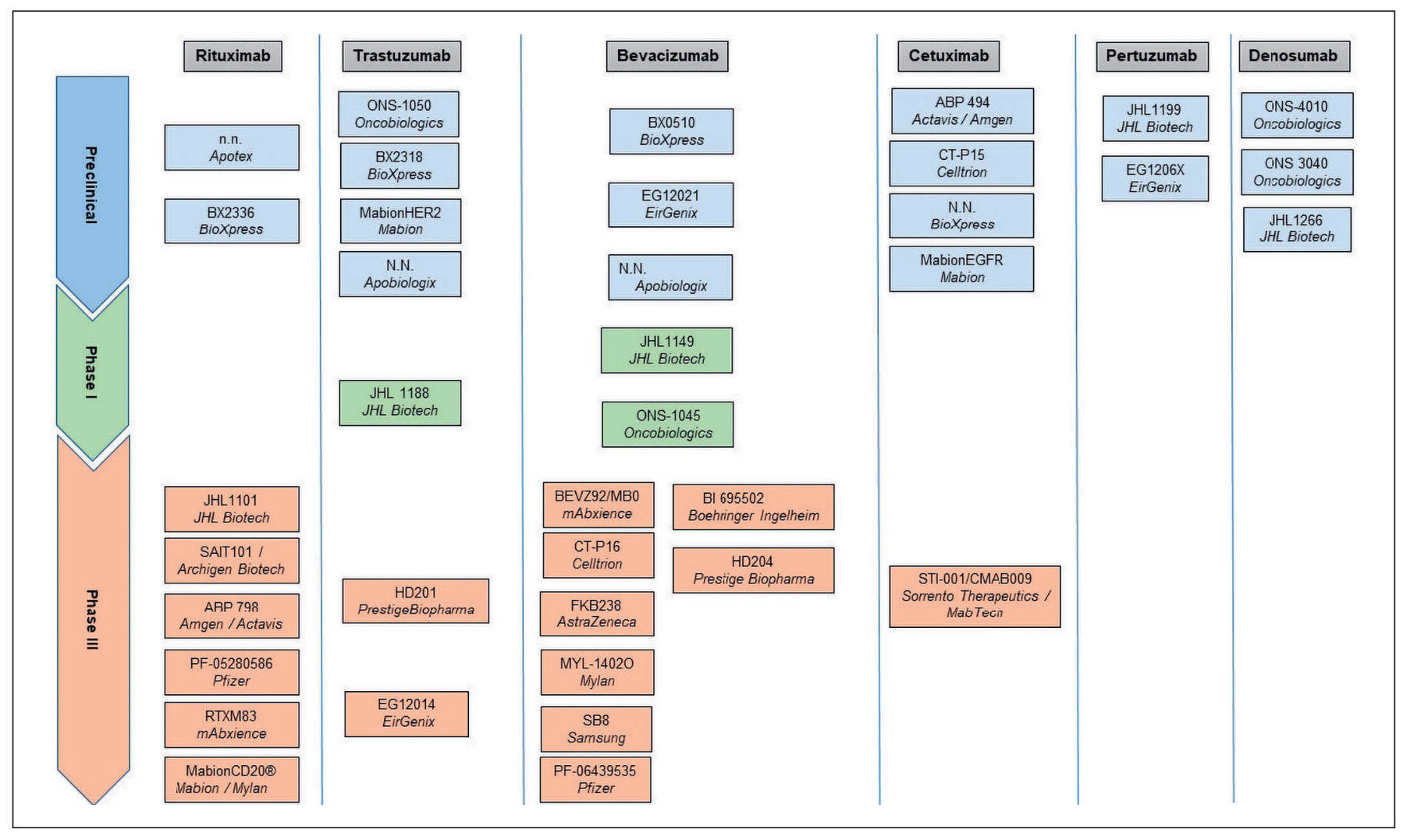

Fig. 1. Pipeline of selected monoclonal antibody biosimilars in oncology.

recurrent non-squamous non-small cell lung cancer (NSCLC), metastatic renal cell carcinoma, metastatic colorectal cancer (CRC), cervical cancer, platinum-resistant or platinum-sensitive recurrent epithelial ovarian, fallopian tube and primary peritoneal cancers, and metastatic breast cancer [22].

The US patent on Avastin expires in 2019, the drug's main European patent expires in 2022. The first bevacizumab biosimilar, ABP 215 (Mvasi ${ }^{\circledR}$; Amgen, Thousand Oaks, CA, USA), has already been approved by the US Food and Drug Administration (FDA) for all eligible indications (i.e., not covered by regulatory exclusivity) authorized for the originator product [23]. This was based on a phase III study in patients with non-squamous NSCLC showing comparable efficacy (overall response rate), safety, and immunogenicity [24]. Several other potential bevacizumab biosimilars are currently in development (fig. 1).

Clinical results have been published for biosimilar candidate BCD-021. A phase III trial in patients with advanced NSCLC showed comparable efficacy and safety of BCD-021 compared to the reference product in combination with paclitaxel plus carboplatin [25]. Moreover, equivalence in objective response rate in patients with advanced non-squamous NSCLC was announced for the bevacizumab biosimilar candidate PF-06439535 [26] in a press release; however, results have not yet been published.

Biosimilars in Oncology
As described above, the forthcoming patent expiries of Avastin in the major markets have encouraged several companies to develop bevacizumab biosimilars, which are in the advanced stage. So far, less attention has been paid to the anti-VEGF antibody aflibercept or antiVEGF-R2 antibody ramucirumab. However, as sales of anti-VEGF ophthalmic products including aflibercept continue to rise, companies are beginning to invest in the development of aflibercept biosimilars, albeit initially with a focus on ophthalmologic indications [27].

\section{Trastuzumab}

Trastuzumab (Herceptin, Roche) is approved for the treatment of human epidermal growth factor receptor 2(HER2)-positive breast cancer and metastatic gastric and gastroesophageal junction adenocarcinomas [28]. The patents on Herceptin expired in Europe in July 2014 and will expire in the US in June 2019 [15].

Based on phase III trials, 5 trastuzumab biosimilars have already been approved for use in the EU: Ontruzant $^{\circledR}$ (SB3, Samsung Bioepis, Incheon, ROK), Herzu$\mathrm{ma}^{\circledR}$ (CT-P6, Celltrion), Ogivri ${ }^{\circledR}$ (MYL-1401O, Mylan, Canonsburg, PA, USA), Kanjinti ${ }^{\circledR}$ (ABP980, Amgen), and Trazimera ${ }^{\circledR}$ (PF-05280014, Pfizer) [29]. Other trastuzumab biosimilars are in various stages of development (fig. 1). 


\section{Beyond the Blockbusters - Monoclonal Antibody Biosimilars in Early Development}

Cetuximab (Erbitux ${ }^{\circledR}$; Eli Lilly, Indianapolis, IN, USA) is a chimeric (mouse/human) IgG1 monoclonal antibody targeted against the epidermal growth factor receptor (EGFR). It is used for the treatment of metastatic CRC and squamous cell carcinoma of the head and neck in conjunction with radiation and chemotherapy [30]. The US patents for the drug expired in 2016 and EU patents expired in 2014 [31]. Several companies, however, are in the process of developing cetuximab biosimilars [32]. Most cetuximab biosimilar candidates are still in preclinical development, such as ABP 494 from Actavis (Parsippany-Troy Hills, NJ, USA)/Amgen, CT-P15 from Celltrion, or Mabion EGFR from Mabion (Lodz, Poland). Only for the biosimilar-biobetter STI-001/CMAB009 developed by Sorrento Therapeutics (San Diego, CA, USA)/ MabTech (Nacka Strand, Sweden), a phase III trial in Chinese metastatic colorectal cancer patients with KRAS wild-type has been successfully completed. The trial tested STI-100 in combination with irinotecan versus irinotecan alone [33]. However, so far, results have only been announced in a press release in 2016 and not yet been published. Interestingly, significantly less adverse events than in studies of the reference product were reported with no hypersensitive reaction compared with more than $10 \%$ of patients in the cetuximab trials. The manufacturer attributed this to a different production method compared to the reference product. Another phase III trial in $R A S / B R A F$ wild-type metastatic CRC patients (NCT03206151) is ongoing.

Panitumumab (Vectibix ${ }^{\circledR}$, Amgen) is also an antiEGFR antibody, but in contrast to cetuximab it is a fully human monoclonal IgG $2 \kappa$ antibody. It is approved for the treatment of metastatic CRC [34]. Since, in comparison to cetuximab, more recent data show at least equivalence if not superiority in terms of effectiveness in the treatment of CRC with a more favorable side effect profile [35], it is not surprising that the industry is interested in developing these biosimilars [36]. The EU patent expires in 2018, the US patent in 2020 [31].

In addition, pertuzumab (Perjeta ${ }^{\circledR}$, Roche), a humanized monoclonal IgG1 antibody against HER2, and trastuzumab emtansine (Kadcyla ${ }^{\circledR}$, Roche), an antibody-drug conjugate of the monoclonal antibody trastuzumab and the maytansine derivative DM1, are the subject of biosimilar activities [36]. Trastuzumab and pertuzumab are directed against different regions of the HER2 receptor [37]. Both antibodies are approved for the treatment of HER2-positive breast cancer: trastuzumab emtansine as monotherapy in metastatic breast cancer [38] and pertuzumab in combination with trastuzumab for metastatic breast cancer or neoadjuvant/adjuvant therapy of locally advanced high-risk breast cancer [39]. Biosimilar candidates for both antibodies are in the preclinical development stage (fig. 1).

Moreover, biosimilar candidates of denosumab (Prolia ${ }^{\circledR} /$ Xgeva $^{\circledR}$, Amgen) are in preclinical development (fig. 1) [36]. Denosumab is a humanized monoclonal inhibitory antibody against the receptor activator of nuclear factor kappa-B ligand (RANKL). It prevents the development of osteoclasts and is used for the treatment of osteoporosis, treatment-induced bone loss, bone metastases, and giant-cell tumor of the bone [40].

\section{Outlook: Considerations for Development of Checkpoint Inhibitor Biosimilars}

Immunotherapy, especially checkpoint inhibition, has yielded unprecedented success in the treatment of cancer. Checkpoint inhibitors like the anti-PD-1 antibodies pembrolizumab and nivolumab have shown efficacy in a wide range of indications with acceptable toxicity. They have altered the treatment landscape in oncology. In some cases, long-lasting responses are achieved which can last up to several years. These observations underscore the curative potential of checkpoint inhibitors in patients with metastatic tumor disease [41]. Therefore, it is not surprising that checkpoint inhibitors such as nivolumab or pembrolizumab are expected to be among the best-selling drugs in 2018 [42]. In Europe, their patent rights will expire in 2026 and in 2028, respectively [15, 41]. Moreover, several checkpoint agonistic and antagonistic antibodies are in late-stage development, and PD-L1-targeted drugs have recently entered the market and are expected to become blockbusters in the near future (2023) [43]. They might also play a role in triple-negative breast cancer. Recently, the IMpassion 130 trial demonstrated a benefit with first-line atezolizumab combined with nab-paclitaxel in triple-negative breast cancer [44]. Based on the remarkable clinical data and high sales forecasts for these checkpoint blockers, companies have invested heavily in immuno-oncology drug development. It is obvious that the pharmaceutical industry will not only invest in the development of new substances but also in that of checkpoint inhibitor biosimilars.

\section{Conclusion}

Since biologicals play an essential role in cancer treatment and are major contributors to the burgeoning healthcare costs, the development of biosimilars is particularly important in oncology. Several biosimilars have recently been approved. Aside from biosimilars of supportive care drugs, in Europe this is currently limited to 
biosimilars of the monoclonal antibodies trastuzumab, rituximab, and bevacizumab. However, the pipeline is full, and we are expecting the landscape of biosimilars to become much more diversified. This might also include biosimilars of checkpoint inhibitors.

As important as cost reduction, however, is the acceptance of biosimilars by both oncologists and patients. This requires that physicians are knowledgeable about the production, regulation, approval, and payment details of biosimilar anticancer drugs and that patients are properly informed. There are frequent concerns by patients, but also by physicians, about the prescription of biosimilars regarding their pharmaceutical quality, their efficacy, especially in extrapolated indications, their safe- ty due to the potential immunogenicity, and their interchangeability with the reference medicine.

Longer follow-up and additional data confirming the safety and efficacy of biosimilars might help to integrate them more and more into clinical practice.

\section{Disclosure Statement}

Prof. Dr. med. Diana Lüftner has received honoraria for advisory board activities and/or oral presentations from Amgen, AstraZeneca, Celgene, Lilly, Loreal, MSD, Mundipharma, Mylan, Novartis, Pfizer, Roche, Teva, and Tesaro. PD Dr. med. Antonia Busse has received honoraria for advisory board activities from Hexal.

\section{References}

1 Weiner GJ: Building better monoclonal antibody-based therapeutics. Nat Rev Cancer 2015; $15: 361-370$

$\checkmark 2$ GaBI Journal Editor: Patent expiry dates for biologicals: 2017 update. GaBI J 2018;7:2934.

3 Ekman N, Vulto AG, Cornes P: Reducing healthcare costs and building trust in biosimilar medicines. GaBI J 2016;5:84-88.

4 Mullard A: 2015 FDA drug approvals. Nat Rev Drug Discov 2016;15:73-77.

5 European Medicines Agency (EMA): Committee for Medicinal Products for Human Use (CHMP). Guideline on similar biological medicinal products, 2014. www.ema.europa. eu/documents/scientific-guideline/guidelinesimilar-biological-medicinal-products-rev1_ en.pdf.

6 Weise M, Bielsky MC, De Smet K, Ehmann F, Ekman N, Giezen TJ, Gravanis I, Heim HK, Heinonen E, Ho K, Moreau A, Narayanan G, Kruse NA, Reichmann G, Thorpe R, van Aerts L, Vleminckx C, Wadhwa M, Schneider CK: Biosimilars: what clinicians should know. Blood 2012;120:5111-5117.

77 Tebbey PW, Varga A, Naill M, Clewell J, Venema J: Consistency of quality attributes for the glycosylated monoclonal antibody Humira ${ }^{\circledR}$ (adalimumab). MAbs 2015;7:805-811.

-8 Schiestl M, Stangler T, Torella C, Cepeljnik T, Toll H, Grau R: Acceptable changes in quality attributes of glycosylated biopharmaceuticals. Nat Biotechnol 2011;29:310-312.

-9 Kim S, Song J, Park S, Ham S, Paek K, Kang M, Chae Y, Seo H, Kim HC, Flores M: Drifts in ADCC-related quality attributes of Herceptin ${ }^{\circledR}$ : impact on development of a trastuzumab biosimilar. MAbs 2017;9:704-714.

10 IMS Institute for Health Informatics: Delivering on the potential of biosimilar medicines. Parsippany, NJ, IMS Institute for Health Informatics, 2016. www.medicinesforeurope. com/wp-content/uploads/2016/03/IMS-Institute-Biosimilar-Report-March-2016-FINAL. $p d f$.
11 IQVIA: Advancing biosimilar sustainability in Europe. A multi-stakeholder assessment. IQVIA, Durham, NC, 2018. www.iqvia.com/ institute/reports/advancing-biosimilar-sustainability-in-europe.

-12 Aapro M, Cornes P, Abraham I: Comparative cost-efficiency across the European G5 countries of various regimens of filgrastim, biosimilar filgrastim, and pegfilgrastim to reduce the incidence of chemotherapy-induced febrile neutropenia. J Oncol Pharm Pract 2012; 18:171-179.

13 Gascon P, Tesch H, Verpoort K, Rosati MS, Salesi N, Agrawal S, Wilking N, Barker H, Muenzberg M, Turner M: Clinical experience with Zarzio ${ }^{\circledR}$ in Europe: what have we learned? Support Care Cancer 2013;21:2925-2932.

-14 Aapro M, Krendyukov A, Schiestl M, Gascon $\mathrm{P}$ : Epoetin biosimilars in the treatment of chemotherapy-induced anemia: 10 years' experience gained. BioDrugs 2018;32:129-135.

15 Derbyshire M: Patent expiry dates for bestselling biologicals: 2017 update. GaBI J 2018; 7:29-34.

16 Agostini C, Canonica GW, Maggi E: European Medicines Agency guideline for biological medicinal products: a further step for a safe use of biosimilars. Clin Mol Allergy 2015;13:3.

17 European Medicines Agency: Applications for new human medicines under evaluation by the Committee for Medicinal Products for Human Use, 2019. www.ema.europa.eu/documents/report/applications-new-humanmedicines-under-evaluation-chmp-january-2019_en.pdf.

18 European Medicines Agency: Mabthera, INN-rituximab.

19 Kim WS, Buske C, Ogura M, Jurczak W, Sancho JM, Zhavrid E, Kim JS, Hernandez-Rivas JA, Prokharau A, Vasilica M, Nagarkar R, Osmanov D, Kwak LW, Lee SJ, Lee SY, Bae YJ, Coiffier B: Efficacy, pharmacokinetics, and safety of the biosimilar CT-P10 compared with rituximab in patients with previously untreated advanced-stage follicular lymphoma: a randomised, double-blind, parallelgroup, non-inferiority phase 3 trial. Lancet Haematol 2017;4:e362-e373.
20 European Medicines Agency: Truxima, INNrituximab.

21 Jurczak W, Ilidia M, Govindbabu KS, Eduardo M, Ascuncion EM, Giri P, Nelson C, Juliana P, Luiza A, Sergey A, Dzhelil O, Pultar P, Cherfi A, Zhu P, Amersdorffer J: A phase III efficacy and safety study of the proposed rituximab biosimilar GP2013 versus rituximab in patients with previously untreated advanced follicular lymphoma. Blood 2016; 128:1809.

22 European Medicines Agency: Avastin, INNbevacizumab.

23 U.S. FDA: FDA approves first biosimilar for the treatment of cancer. Media release, 2017. www.fda.gov/newsevents/newsroom/pressannouncements/ucm576112.htm.

24 Casak SJ, Lemery SJ, Chung J, Fuchs C, Schrieber SJ, Chow ECY, Yuan W, Rodriguez L, Gwise T, Rowzee A, Lim S, Keegan P, McKee AE, Pazdur R: FDA's approval of the first biosimilar to bevacizumab. Clin Cancer Res 2018;24:4365-4370.

25 Filon O, Orlov S, Burdaeva O, Kopp MV, Kotiv B, Alekseev S, Pecheniy A, Stroyakovskiy D, Gladkov O, Khorinko A, Matrosova M, Galiulin R, Skopin P, Mukhametsina G, Odarchenko S, Kulik S, Kulyaba J, Adamchuk G, Vinnyk Y, Tjulandin S: Efficacy and safety of BCD-021, bevacizumab biosimilar candidate, compared to Avastin: results of international multicenter randomized double blind phase III study in patients with advanced non-squamous NSCLC. J Clin Oncol 2015;33: 8057.

26 Peraza MA, Rule KE, Shiue MHI, Finch GL, Thibault S, Brown PR, Clarke DW, Leach MW: Nonclinical assessments of the potential biosimilar PF-06439535 and bevacizumab. Regul Toxicol Pharmacol 2018;95:236-243.

27 Biosimilar Development: Anti-VEGF and anti-VEGF-R biosimilars and biosuperiors of Avastin, Cyramza, Eylea and Lucentis - 2017; new report launched. www.biosimilardevelopment.com/doc/anti-vegf-and-anti-vegf-rbiosimilars-and-biosuperiors-of-avastin-cyramza-eylea-and-lucentis-new-reportlaunched-0001. 
28 European Medicines Agency: Herceptin, INN-trastuzumab.

29 GaBI Online: Generics and Biosimilars Initiative. Biosimilars approved in Europe 2011. www.gabionline.net/Biosimilars/General/Biosimilars-approved-in-Europe.

30 European Medicines Agency: Erbitux, INNcetuximab.

-31 Derbyshire M: Patent expiry dates for biologicals: 2016 update. GaBI J 2017;6:27-30.

32 DiGrande S: Cetuximab biosimilars are on the horizon. Center for Biosimilars, 2018. www.centerforbiosimilars.com/news/cetuximab-biosimilars-are-on-the-horizon.

33 News provided by Sorrent Therapeutics, Inc. San Diego, CA: Sorrento announces positive data from phase 3 studies of biosimilar antibodies, STI-001 and STI-002. www.prnewswire.com/news-releases/sorrento-announcespositive-data-from-phase-3-studies-of-biosimilar-antibodies-sti-001-andsti-002-300202054.html.

34 European Medicines Agency: Vectibix, INNpanitumumab.

-35 Taniguchi H, Yamanaka T, Sakai D, Yamazaki K, Muro K, Peeters M: Panitumumab versus cetuximab in patients with wild-type KRAS exon 2 metastatic colorectal cancer who received prior bevacizumab therapy: a combined analysis of individual patient data from ASPECCT and WJOG6510G. J Clin Oncol 2018;36:745.

36 The Center for Biosimilars: Assessing the Next Wave of Biosimilars. June 18, 2018. www.centerforbiosimilars.com/contributor/ $z s / 2018 / 06$.

37 Wong DJ, Hurvitz SA: Recent advances in the development of anti-HER2 antibodies and antibody-drug conjugates. Ann Transl Med 2014;2:122.

38 European Medicines Agency: Kadcyla, INNtrastuzumab emtansine.
39 European Medicines Agency: Perjeta, INNpertuzumab.

40 European Medicines Agency: Xgeva, INNdenosumab.

41 Collin M: Immune checkpoint inhibitors: the battle of giants. Pharm Pat Anal 2017;6:135137.

42 Mullard A: Top product sales forecasts for 2018. Nat Rev Drug Discov 2018;17:86.

43 Mullard A: 2017 FDA drug approvals. The FDA approved 46 new drugs last year, the highest total in more than two decades. Nat Rev Drug Discov 2018;17:81-85.

44 Schmid P, Adams S, Rugo HS, Schneeweiss A, Barrios $\mathrm{CH}$, Iwata $\mathrm{H}$, Dieras V, Hegg R, Im SA, Shaw Wright G, Henschel V, Molinero L, Chui SY, Funke R, Husain A, Winer EP, Loi S, Emens LA; IMpassion130 Trial Investigators: Atezolizumab and nab-paclitaxel in advanced triple-negative breast cancer. $\mathrm{N}$ Engl J Med 2018;379:2108-2121.

45 Stebbing J, Baranau Y, Baryash V, Manikhas A, Moiseyenko V, Dzagnidze G, Zhavrid E, Boliukh D, Stroyakovskii D, Pikiel J, Eniu A, Komov D, Morar-Bolba G, Li RK, Rusyn A, Lee SJ, Lee SY, Esteva FJ: CT-P6 compared with reference trastuzumab for HER2-positive breast cancer: a randomised, double-blind, active-controlled, phase 3 equivalence trial. Lancet Oncol 2017;18: 917-928.

46 Von Minckwitz G, Colleoni M, Kolberg HC, Morales S, Santi P, Tomasevic Z, Zhang N, Hanes V: Efficacy and safety of ABP 980 compared with reference trastuzumab in women with HER2-positive early breast cancer (LILAC study): a randomised, double-blind, phase 3 trial. Lancet Oncol 2018; 19:987-998.

47 Pivot X, Bondarenko I, Nowecki Z, Dvorkin M, Trishkina E, Ahn JH, Im SA, Sarosiek T, Chatterjee S, Wojtukiewicz MZ, Shparyk Y,
Moiseyenko V, Bello M 3rd, Semiglazov V, Lee Y, Lim J: A phase III study comparing SB3 (a proposed trastuzumab biosimilar) and trastuzumab reference product in HER2-positive early breast cancer treated with neoadjuvant-adjuvant treatment: final safety, immunogenicity and survival results. Eur J Cancer 2018;93:19-27.

48 Pegram M, Tan-Chiu E, Freyman A, Vana A, Hilton F, Zacharchuk C, Ewesuedo R: A randomized, double-blind study of PF-05280014 (a potential trastuzumab biosimilar) vs. trastuzumab, both in combination with paclitaxel, as first-line treatment for HER2-positive metastatic breast cancer. Ann Oncol 2017;28:mdx365.001a.

49 Lammers PE, Dank M, Masetti R, Abbas R, Hilton F, Coppola J, Jacobs I: Neoadjuvant PF-05280014 (a potential trastuzumab biosimilar) versus trastuzumab for operable HER2+ breast cancer. Br J Cancer 2018;119: 266-273.

50 Rugo HS, Barve A, Waller CF, HernandezBronchud M, Herson J, Yuan J, Sharma R, Baczkowski M, Kothekar M, Loganathan S, Manikhas A, Bondarenko I, Mukhametshina G, Nemsadze G, Parra JD, Abesamis-Tiambeng ML, Baramidze K, Akewanlop C, Vynnychenko I, Sriuranpong V, Mamillapalli G, Ray S, Yanez Ruiz EP, Pennella E; Heritage Study Investigators: Effect of a proposed trastuzumab biosimilar compared with trastuzumab on overall response rate in patients with ERBB2 (HER2)-positive metastatic breast cancer: a randomized clinical trial. JAMA 2017;317:37-47.

51 Casak SJ, Lemery SJ, Chung J, Fuchs C, Schrieber SJ, Chow ECY, Yuan WS, Rodriguez L, Gwise T, Rowzee A, Lim S, Keegan P, McKee AE, Pazdur R: FDA's approval of the first biosimilar to bevacizumab. Clin Cancer Res 2018;24:4365-4370. 